\title{
KONSTRUKSI DAN KAPASITAS ALAT PENGERING IKAN TENAGA SURYA SISTEM BONGKAR-PASANG
}

\author{
Youce M Bintang, Jenki Pongoh dan Hens Onibala
}

Fakultas Perikanan dan Ilmu Kelautan, Universitas Sam Ratulangi, Manado, Sulawesi Utara

\begin{abstract}
ABSTRAK
Pada umumnya nelayan atau pengusaha ikan melakukan pengeringan ikan secara tradisional yaitu dengan memanfaatkan tenaga surya secara langsung. Pengeringan cara ini biasanya dilakukan dengan meletakkan produk di atas tikar, hamparan lantai semen atau anyaman bambu dan ditempatkan di bawah sinar matahari.

Kondisi tersebut di atas menimbulkan gagasan untuk merancang dan membuat alat pengering ikan tipe Efek Rumah Kaca (ERK)-hybrid, yang dapat memanfaatkan panas dari tenaga surya dan dapat menggunakan sumber energi lainnya seperti kompor. Alat pengering ini bisa digunakan untuk jangka waktu yang lama, karena menggunakan bahan alumunium sebagai bahan dasar, sehingga mudah dibersihkan dan mudah dalam penyimpanan. Dengan bobot alat yang ringan, dimensi panjang dan lebar hanya $80 \mathrm{~cm} \times 80 \mathrm{~cm} \times 188.2 \mathrm{~cm}$, alat ini tidak memerlukan ruang yang besar jika disimpan,

Penelitian ini menggunakan metode eksperimen yaitu suatu bentuk penelitian yang dilakukan dengan cara mengubah suatu keadaan untuk melihat kejadian yang timbul akibat dari perubahan itu. Dalam perancangan dan pembuatan 1 (satu) unit alat pengering tenaga surya sistem bongkar-pasang ini membutuhkan biaya sebesar Rp. 3.853.500,- dengan daya tampung maksimal 15-16 Kg. Capaian suhu maksimal dalam alat pengering sampai $50^{\circ} \mathrm{C}$ dengan suhu luar maksimal $38^{\circ} \mathrm{C}$. Pada pengeringan ikan selama 14 jam dengan suhu rata-rata $45^{\circ} \mathrm{C}$ dapat menurunkan kadar air ikan sampai $37^{\circ} \mathrm{C}$ dan dengan nilai organoleptik $>7$. Hal ini sesuai dengan SNI yaitu kadar air maksimal $40 \%$ dan nilai organoleptik minimal 7.
\end{abstract}

Kata kunci: Pengolahan, suhu, desain, daya awet, biaya, alat pengering ikan, alumunium.

\section{PENDAHULUAN}

Proses pengolahan maupun pengawetan merupakan usaha untuk meningkatkan mutu simpan dan daya awet produk perikanan pasca panen. Tujuan dari pengolahan dan pengawetan ikan pada prinsipnya merupakan usaha untuk mengatasi kelebihan hasil produksi dan sekaligus mempertahankan kualitas ikan sebelum dipasarkan ataupun dikonsumsi, meningkatkan nilai jual ikan, sebagai bahan diversifikasi makanan dan untuk memperpanjang masa simpan ikan (Afrianto dan Liviawaty, 1989).

Berbagai cara pengawetan ikan secara tradisional telah dilakukan saat ini dengan tujuan untuk mengurangi kadar air dalam tubuh ikan, sehingga tidak dapat memberikan kesempatan kepada bakteri (mikroba) untuk hidup dan berkembang, serta mempertahankan daya awet ikan (Berhimpon, $d k k$., 2002). Salah satu upaya pengawetan ikan yang banyak dilakukan adalah dengan cara pengeringan. Pada prinsipnya pengeringan ikan merupakan suatu metode untuk mengeluarkan atau menghilangkan sebagian air dari suatu bahan dengan cara menguapkan air dalam bahan tersebut dengan menggunakan energi panas (Harikedua, dkk., 1991).

Pada umumnya nelayan atau pengusaha ikan melakukan pengeringan ikan secara tradisional yaitu dengan memanfaatkan tenaga surya secara langsung. Pengeringan cara ini biasanya dilakukan dengan meletakkan produk di atas jaring ikan, tikar, hamparan lantai semen atau anyaman bambu dan ditempatkan di bawah sinar matahari. Metode ini tidak higienis dan memungkinkan produk yang dikeringkan kehilangan sebagian beratnya, karena dimakan serangga, burung, kucing atau hewan lainnya. Selain itu juga, produk akan dengan mudah terkena debu dan proses pengeringan akan tertunda jika hujan, sehingga hasil yang diperoleh tidak maksimal, serta jumlah produksi yang dihasilkan tidak sesuai harapan.

Kondisi tersebut di atas menimbulkan gagasan untuk merancang dan membuat alat pengering ikan tipe Efek Rumah Kaca (ERK)hybrid, yaitu alat pengering ikan yang memanfaatkan panas dari tenaga surya dan dapat menggunakan sumber energi lainnya seperti kompor.

Penelitian ini bertujuan untuk membuat konstruksi dan mengetahui kapasitas alat 
pengering ikan tenaga surya sistem bongkarpasang.

\section{METODOLOGI PENELITIAN}

\section{Bahan dan alat penelitian}

Bahan-bahan yang digunakan dalam penelitian ini adalah: alumunium hollow 3,5", $0,5 \times 1 ", 1 \times 2 "$, tiang slide cokelat, plastik acrylic, seng plat, les pancing kecil, les pancing besar, magnet cokelat, engsel piano, paku rivet, paku sekrup 0,25", spicot dan lem silicone.

Alat yang digunakan adalah: mesin potong alumunium, gergaji besi, bor listrik, mata bor listrik $(+)$ dan $(-)$, mata bor beton, obeng $(+)$ dan $(-)$, tang, rivet, cuter, meter gulung, alat siku $45^{\circ}$, kikis dan kertas ampelas.

\section{Tata laksana penelitian}

1. Mempersiapkan bahan dan alat yang akan digunakan.

2. Memotong bahan-bahan sesuai dengan ukuran yang sudah ditentukan.

3. Pembuatan rangka alat pengering sesuai dengan bentuk/pola yang sudah dirancang sebelumnya.

4. Pemasangan rangka alat pengering yang diawali dengan merangkai kaki dan rak-I, kemudian rak-II dan seterusnya sampai rakIV. Sebelum rak-II digabungkan dengan rakI maka terlebih dahulu memasukkan plastik acrylic pada bagian kiri, kanan dan bagian belakang, kecuali bagian depan yang disebut pintu.

5. Merangkai bagian penutup dari alat pengering.

6. Menghitung besar biaya yang digunakan untuk pembuatan 1 unit alat pengering tenaga surya sistem bongkar-pasang.

7. Menghitung kapasitas alat terhadap ikan yang dapat dikeringkan.

8. Pengujian alat dengan cara mengeringkan ikan.

\section{HASIL DAN PEMBAHASAN}

\section{Rancang bangun alat pengeringan ikan tenaga surya sistem bongkar-pasang}

Dalam proses pembuatan alat pengering ikan, tahapan yang dilakukan yaitu merancang desain alat, pemilihan dan pembelian bahan, pembuatan alat, menghitung kapasitas alat, menghitung anggaran pembuatan alat dan mengetahui manfaat alat pengering ikan.

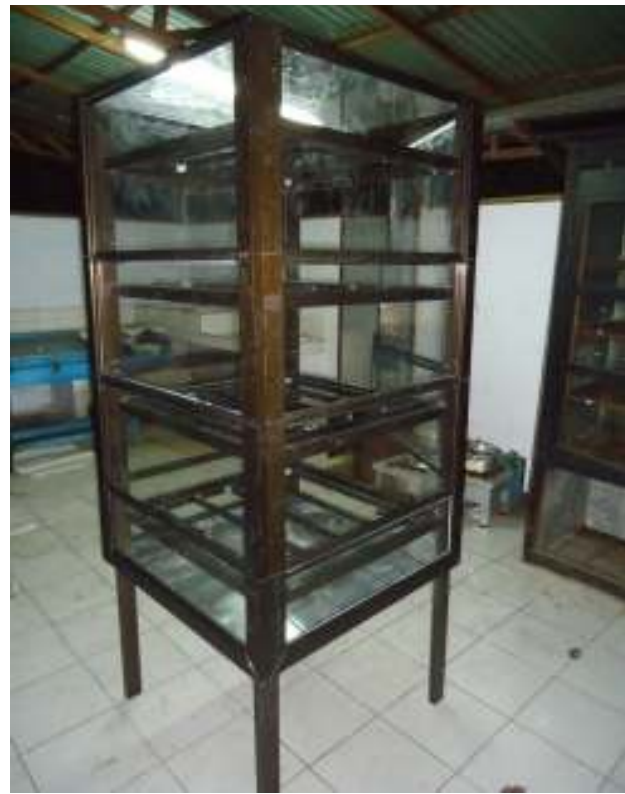

Gambar 1. Alat pengering ikan tenaga surya sistem bongkar-pasang.

\section{Desain alat}

Merancang merupakan kegiatan awal dari usaha merealisasikan suatu produk yang keberadaannya dibutuhkan oleh masyarakat untuk meringankan hidupnya dengan memanfaatkan fasilitas penunjang yang berhubungan dengan kegiatan merancang. Perancangan itu sendiri terdiri dari serangkaian kegiatan yang berurutan. Saat ini kegiatan merancang suatu gambar seperti desain rumah atau alat atau apapun dengan alat bantu komputer, pasti menggunakan program atau software desain, seperti Autocad, Archicad dan Google Sketchup atau program olah grafik lainnya. Pada kegiatan merancang alat pengering ikan tenaga surya sistem bongkar-pasang kali ini, program yang digunakan adalah Google Sketchup 6. Program ini dipilih karena mudah dalam pengoperasiannya serta memiliki fitur yang cukup lengkap untuk membuat sebuah desain.

\section{Kapasitas alat}

Berdasarkan hasil penelitian yang dilakukan dapat diketahui bahwa alat pengering ini dapat menampung ikan untuk dikeringkan sebanyak $8-9 \mathrm{Kg}$ jika ikan yang sudah dibelah dihampar di plat alumunium pada tiap rak dan bila digantung di tiap rak, maka bisa mencapai 15-16 $\mathrm{Kg}$, dengan jenis ikan layang yang berukuran panjang berkisar antara $23-25 \mathrm{~cm}$ dan berat $147-$ 150 gram/ekor.

\section{Anggaran pembuatan alat}

Biaya yang digunakan dalam pembuatan alat ini relatif besar, tetapi perlu adanya penelitian 
lanjutan untuk daya tahan alat, karena jika dibandingkan dengan alat pengering yang terbuat dari kayu, tidak bisa digunakan untuk jangka waktu yang lama karena cepat rusak. Berbeda dengan alat pengering ini, dengan bahan dasar atau rangka terbuat dari alumunium, alat ini mudah dibersihkan setelah digunakan, tahan rayap dan tahan api sehingga bisa digunakan untuk jangka waktu yang lama. Dalam pembuatan alat pengering ikan tenaga surya sistem bongkar-pasang harga bahan yang digunakan lebih tinggi dari bahan alumunium biasa, karena bahan yang digunakan adalah alumunium cokelat.

Tabel 1. Rincian Anggaran Bahan Untuk 1 Unit Alat Pengering Tenaga Surya Sistem Bongkar-Pasang.

\begin{tabular}{lrlrr}
\hline \multicolumn{1}{c}{ BAHAN } & JUMLAH & $\begin{array}{c}\text { HARGA } \\
\text { SATUAN } \\
\text { (Rp) }\end{array}$ & \multicolumn{1}{c}{$\begin{array}{c}\text { TOTAL } \\
\text { (Rp) }\end{array}$} \\
\hline Les pancing kecil & 7 & Ujg & 20.000 & 140.000 \\
Les pancing besar & 1 & Ujg & 23.000 & 23.000 \\
Tiang sliding cokelat & 3 & Ujg & 104.000 & 312.000 \\
Hollow alum 3.5" & 3 & Ujg & 55.000 & 165.000 \\
Hollow alum 0.5"x1" & 3 & Ujg & 39.000 & 117.000 \\
Hollow alum 1"x2" & 2 & Ujg & 104.000 & 208.000 \\
Magnet cokelat & 4 & Bh & 5.000 & 20.000 \\
Engsel piano & 1 & Roll & 27.500 & 27.500 \\
Paku rivet & 1 & Dus & 68.000 & 68.000 \\
Paku sekrup 0.25" & 1 & Dus & 65.000 & 65.000 \\
Silicone sealant & 2 & Btl & 30.000 & 60.000 \\
Kawat ram & 1 & M & 22.500 & 22.500 \\
Seng plat & 3 & Lbr & 36.000 & 108.000 \\
Spicot & 1 & Ujg & 47.500 & 47.500 \\
Acrylic & 2 & Lbr & 485.000 & 970.000 \\
Biaya pembuatan & & & & 1.000 .000 \\
Biaya lain-lain & & & & 500.000 \\
\hline & & & TOTAL & $\mathbf{3 . 8 5 3 . 5 0 0}$ \\
\hline
\end{tabular}

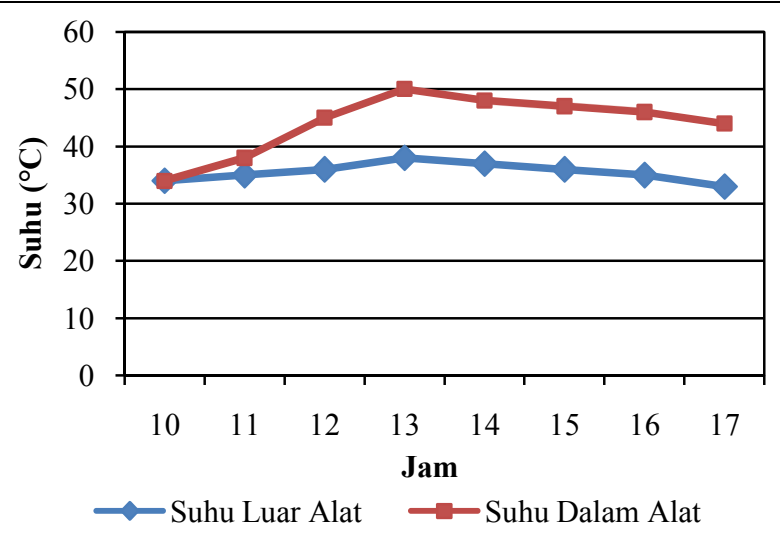

Gambar 2. Grafik perbandingan suhu luar dan suhu di dalam alat.

\section{Manfaat Alat}

Alat pengering tenaga surya dengan sistem bongkar-pasang ini dirancang untuk bisa digunakan di luar ruangan dengan bantuan energi pengeringan sinar matahari/tenaga surya serta aman dari serangga dan debu dan bila diperlukan bisa juga digunakan untuk proses pengeringan dengan bantuan energi panas dari kompor.

Kelebihan lain juga dari rancangan alat ini adalah bisa dengan mudah untuk dipindahpindahkan karena proses bongkar-pasangnya sangat mudah dilakukan, bahkan dengan 1 (satu) orang alat ini bisa dibongkar-pasang. Apabila diperlukan alat ini bisa hanya menggunakan satu atau dua rak saja dalam proses pengeringan, tergantung pada kebutuhan atau jumlah bahan yang akan dikeringkan.

\section{Penerapan Alat Pada Produk Perikanan \\ 1. Suhu}

Tinggi rendahnya suhu di dalam alat pada saat proses pengeringan sangat dipengaruhi oleh teriknya sinar matahari. Perbandingan suhu luar dan suhu di dalam alat pada saat pengeringan ikan dengan tenaga surya dapat dilihat pada Gambar 2.

\section{Efisiensi Alat dan Penerapannya pada Produk Perikanan}

Dari hasil pengeringan ikan dengan alat pengering ikan tenaga surya sistem bongkarpasang ini selama 14 jam dengan suhu rata-rata $45^{\circ} \mathrm{C}$ dapat menurunkan berat pada ikan asin hingga mencapai $37 \%$.

\section{KESIMPULAN DAN SARAN}

\section{Kesimpulan}

Dari hasil penelitian dapat disimpulkan bahwa:

1. Alat pengering ikan tenaga surya sistem bongkar pasang ini sangat mudah dalam bongkar-pasangnya, mudah dibersihkan, mudah dalam penyimpanan serta lebih tahan lama dibandingkan dengan alat pengering dengan bahan dasar kayu dan bisa menggunakan kompor sebagai sumber panas lainnya.

2. Dengan dimensi $80 \mathrm{~cm} \times 80 \mathrm{~cm} \times 188,2 \mathrm{~cm}$ alat pengering ikan ini dapat menampung ikan sampai 8-9 Kg jika ikan yang sudah dibelah dihampar di plat alumunium pada tiap rak dan bila digantung di tiap rak, maka bisa mencapai 15-16 Kg, dengan jenis ikan layang yang berukuran panjang berkisar antara $23-25 \mathrm{~cm}$ dan berat 147-150 gram/ekor. Rangka terbuat dari alumunium dan ditutupi dengan acrylic transparan.

3. Total biaya yang dibutuhkan dalam pembuatan 1 unit alat pengering tenaga surya sistem bongkar-pasang ini sebesar Rp. 3.853.500,-.

4. Suhu maksimal dalam alat pengering sampai $50^{\circ} \mathrm{C}$ dengan suhu luar maksimal $38^{\circ} \mathrm{C}$ pada 
pengeringan ikan dengan menggunakan tenaga matahari.

5. Pada pengeringan ikan selama 14 jam dengan suhu rata-rata $45^{\circ} \mathrm{C}$ dapat menurunkan kadar air ikan sampai $37^{\circ} \mathrm{C}$ dan dengan nilai organoleptik $>7$. Hal ini sesuai dengan SNI yaitu kadar air maksimal $40 \%$ dan nilai organoleptik minimal 7.

\section{Saran}

Berdasarkan hasil penelitian yang dilakukan, maka dapat disarankan beberapa hal, yaitu:

1. Lubang tempat keluarnya uap air sebaiknya ditutup pada saat awal pengeringan sampai pada waktu tertentu, agar suhu di dalam alat bisa lebih tinggi lagi.

2. Bisa menggunakan solar dryer agar capaian suhu di dalam alat bisa lebih meningkat.

3. Agar suhu di dalam alat pengering bisa lebih meningkat, gunakanlah kaca cekung untuk memantulkan sinar matahari.

4. Bersihkan alat setelah proses pengeringan, agar bisa digunakan untuk jangka waktu yang lebih lama lagi.

5. Simpan di tempat yang aman.

\section{DAFTAR PUSTAKA}

Afrianto, E., dan E. Liviawaty., 1989. Pengawetan dan Pengolahan Ikan. Kanisius. Yogyakarta.

Anonimous, 2009. Model Pengeringan Ikan Efek Rumah Kaca Dengan pemanfaatan Sumber Energi Terbarukan. www.scribd.com/doc/31661030/ContohProposal-Skripsi-Tesis Di akses pada Kamis, 19 Juni, 2012, 7:33:22 AM

Anonimous, 2012. Riset Alat Pengering Tenaga Surya http:// kabarbengkulu.com/kabar-bengkulu/read/unib riset alat pengering tenaga surya/ Di akses pada Kamis, 19 Juni, 2012, 8:10:54 AM
Berhimpon, S., F. G. Ijong dan P. Moniharapon, 2002. Penilaian indera. Penuntun Praktikum. FPIK. UNSRAT. Manado.

Berhimpon, S., H. Dien, R. Montolalu, 2002. Processing and The Prospect of Katsuobushi (Ikan kayu) of North Sulawesi, Indonesia: A Review. Fish Handling and Processing Laboratory. Faculty of Fisheries and Marine Science. Sam Ratulangi University. Manado.

Buckle, K.A., R.A. Edward, G.H. Fleet, M. Wooton. 1985. Ilmu Pangan. Penerjemah Hari Purnomo dan Adiono. UI. Jakarta.

Ernita Y, Sandra M, dan Feri M, 2009. Pengembangan Teknologi Solar Dryer Untuk Pengeringan Ikan. Makalah Seminar Hasil Penelitian Politeknik Pertanian Negeri Payakumbuh pada Februari 2009 di Politeknik Pertanian Negeri Payakumbuh.

Harikedua, J. 1985. Dasar-dasar Pengawetan dan Pengolahan Pangan. Fakultas Perikanan UNSRAT. Manado.

Harikedua, J.W.; B. Kaseger; G. Sanger; L. Setyaningsih; A. Sinyal; E. Pandey; dan S. Dolonseda,. 1991. Pengantar Pengolahan Hasil Perikanan. Fakultas Perikanan UNSRAT. Manado.

Harikedua, J.W., 1995. Pengantar Teknologi Pengolahan Hasil Perikanan. Fakultas Perikanan dan Ilmu Kelautan. Universitas Sam Ratulangi.

LIPTAN, 2001. Alat pengering Surya Sederhana yang Serba Guna. Lembar Informasi Pertanian. http://pustaka.litbang.deptan.go.id/ agritek/lip50103.pdf Di akses pada Kamis, 19 Juni, 2012, 7:50:58 AM

Mantjoro, E. 1981. Metodologi Penelitian. Fakultas Perikanan Universitas Sam Ratulangi. Manado. Universitas Sam Ratulangi. Manado.

Moeljanto, R.. 1982. Penggaraman dan Pengeringan Ikan. Penerbit PT. Penebar swadaya. Jakarta.

Moeljanto. 1992. Pengolahan dan Pengawetan Hasil Perikanan. Penebar Swadaya. Jakarta.

Murniyati, A. S. Dan Sunarman, 2000. Pendinginan, Pembekuan dan pengawetan Ikan. Kanisius, Jakarta. 